\title{
Prevalence and causes of visual impairment and blindness among adults with diabetes mellitus aged 40 years and older receiving treatment at government health facilities in the Mopani District, South Africa
}

\author{
RG Mabaso* and OA Oduntan ${ }^{\dagger} *$
}

*Department of Health Studies, College of Human Sciences, University of South Africa, Pretoria, South Africa. PO Box 392, UNISA, Pretoria 0003 South Africa

$\uparrow$ Discipline of Optometry, School of Health Sciences, University of KwaZulu-Natal, Durban, South Africa. Private Bag X54001, Durban 4000 South Africa

*<mabaso@mweb.co.za>, †<oduntanoa@ukzn.ac.za>

Received 18 July 2013; revised version accepted 19 March 2014

\section{Abstract}

This article presents part of the findings of a study conducted to assess the prevalence and causes of visual impairment (VI) and blindness among adults with diabetes mellitus (DM) receiving treatment at the government health facilities in the Mopani District, South Africa. This health facility-based cross-sectional study was conducted among 225 Black South African diabetics (161 females and 64 males) aged 40-90 years (mean= $61.50 \pm 10.49)$ years at seven different health care facilities. All the participants were examined for VI using an auto-refractor, pinhole disc, an ophthalmoscope, and a logMAR chart. Visual impairment was defined as visual acuity (VA) of worse than $6 / 9.5$ but better and equal to $3 / 60$, and blindness as VA of worse than 3/60 to no light perception. The prevalence of uncompensated VI and blindness in the right eyes was 70.6 and 3.6\%, respectively. In the left eyes, the prevalence was
72 and $3.1 \%$ for VI and blindness respectively. The prevalence of blindness remained the same after optical compensation. The leading causes of uncompensated VI and blindness in both eyes were uncorrected refractive error (RE) $(49.5 \%)$, cataract $(24.7 \%)$, diabetic retinopathy (3.8\%) and glaucoma (2.2\%). Following optical compensation, the prevalence of compensated VI and blindness in the right eyes was 41.3 and $3.6 \%$, respectively and in the left eyes, the prevalence was 42.2 and $3.1 \%$, respectively. Uncompensated $\mathrm{RE}$ and cataract were the common causes of VI and blindness in this sample. The socio-economic status of this population might have contributed to these findings. These results indicate the need for affordable vision examination and spectacles provision as well as cataract surgery services in this population. (S Afr Optom 2014 73(1) 8-15)

Key Words: Blindness, diabetes mellitus, diabetic retinopathy, refractive error, visual impairment

*BOptom(UNIN) CAS(NECO) MPH(UL) DLitt et Phil(UNISA)

${ }^{\dagger} \mathrm{BSc}($ Hons)Optom $\mathrm{PhD}$

This article is part of a thesis submitted by RG Mabaso to the University of South Africa in accordance with the requirements for the degree of Doctor of Literature and Philosophy (DLitt et Phil) under the supervision of Professor OA Oduntan. 


\section{Introduction}

Diabetes mellitus (DM) is one of the most common non-communicable diseases globally and is one of the most challenging epidemics of the 21 century $^{1}$. Globally, the number of adults with DM aged 20-79 years old is projected to increase from 366 million $(8.3 \%)$ in 2011 to 552 million (9.9\%) by $2030^{2}$. It is estimated that above $80 \%$ of these 552 million people with DM will live in developing countries ${ }^{2}$. In the subSaharan African region, the number of people with DM is expected to increase from 14.7 million in 2011 to 28 million by $2030^{2}$. In South Africa, the number of people (20-79 years) with DM was estimated at 1.9 million people in 2011 and at least $78 \%$ of the people may be undiagnosed ${ }^{2}$.

In many developed nations, DM is among the leading causes of visual impairment (VI) and blindness ${ }^{1}$. As one of the complications of DM, diabetic retinopathy (DR) has been identified as the leading cause of new cases of VI and blindness among adults aged between 20-74 years in developed countries ${ }^{3}$. DR results from damage to the capillary walls of retinal blood vessels due to chronic hyperglycaemia. This damage may lead to aneurysms, the rupture of which results in retinal haemorrhage, ischemia and micro-infarctions that may lead to vision loss ${ }^{4}$.

In the United States, DR causes 12000 to 24000 new cases of blindness each year ${ }^{3}$. In North America, $3.6 \%$ of patients with Type $1 \mathrm{DM}$ and $1.6 \%$ of patients with Type $2 \mathrm{DM}$ are legally blind due to $\mathrm{DR}^{4}$. In England and Wales, about 1000 patients are registered as blind or partially sighted each year, with DR being the most common cause of blindness among economically active individuals ${ }^{4}$.

In South Africa, DR is the third leading cause of blindness, after cataract and glaucoma and accounts for about $8 \%$ of the total number of blind people in the country; a prevalence that is on the increase ${ }^{5}$; indicating the need for both government and the private sector to take appropriate measures to create awareness about the ocular complications of DM. The increase in the prevalence of DM suggests that more people with this condition will become visually impaired or blind if steps are not taken to prevent the incidence of DM and its ocular complications.

No previous report on VI and blindness among people with DM in the Mopani District was found in the literature. Therefore, the purpose of this paper is to report on the prevalence and causes of visual impairment and blindness among adults with DM aged 40 years and older in the Mopani District, South Africa.

\section{Method}

This study was approved by the Health Studies Research and Ethics committee (HSREC) of the University of South Africa (UNISA) and permission was obtained from the relevant authorities before the commencement of the study. All the ethics protocols were observed during the study. The study sites were seven public health care facilities in the Mopani District Municipality. They included four Clinics, one Health Centre, and two Hospitals. The participants were all Black South Africans of both sexes with DM, aged 40-90 years and living in the District. No reliable data was available in the Mopani District Information Office on the number of Black South African diabetics. During the period of this study (May to December 2011), the total number of Black South African diabetics registered at the seven Public health facilities included in this study was 721 . Of this number, $25(3.5 \%)$ were $<40$ years and these included 15 females and 10 males. Others, $696(96.5 \%)$ were $\geq 40$ years and included $475(68.2 \%)$ females and $221(31.8 \%)$ males. Two hundred and twenty five (225) of those who satisfied the selection criteria and were receiving diabetes services from the targeted public health facilities participated in the study and each signed the relevant consent forms.

Each participant's demographic details were noted and following a short case history, distance visual acuities (VA) were measured using a logMAR (Landolt "C") chart at a distance of 4 metres. The test procedure was properly explained to the participants. The left eye was covered while the right eye was being tested and vice versa. The participant was asked to report where the gap of each "C" on the chart was facing (left, right, up or down) beginning from the largest (6/60) line to the smallest line that they could see. The acuity values were recorded in logMAR line scoring format as explained by previous authors ${ }^{6,7}$.

Visual impairment and blindness were classified according to the World Health Organization (WHO) 
definitions of visual impairment ${ }^{8}$. Participants with VA equal to or better than $6 / 9.5$ were categorised as having no visual impairment (VI). Mild VI was defined as VA of worse than $6 / 9.5$, but equal to or better than $6 / 18$ in the better eye, moderate VI as VA of worse than $6 / 18$ but equal to or better than $6 / 60$, severe VI as VA of worse than $6 / 60$ but equal to or better than $3 / 60$, blindness as VA worse than $3 / 60$ to no light perception.

Subsequently, auto-refraction was performed on both eyes of the participants to determine distance refractive errors (RE). Best corrected VA was measured monocularly with the patient wearing trial lenses from the auto-refraction results and a pinhole disc placed over the trial lenses. RE was recorded as the cause of VI where VA improved to 6/9.5 or better with optical correction and a pinhole. However, where there was no improvement in VA, a direct ophthalmoscope was used to examine the external and internal structures of the eye to determine the cause of VI or blindness. Amblyopia was reported as the cause of VI only for participants with VA of 20/40 or worse and no apparent organic lesion and satisfying one or more of the following criteria: 1) esotropia, exotropia or vertical tropia at 4 meters fixation, or exotropia or vertical tropia at 0.5 meters fixation, or 2) Anisometropia of 2 dioptres (D) or higher or 3 ) Bilateral ametropia of $+6.00 \mathrm{D}$ or higher9.

Only the primary cause of VI was recorded. Where there were two or more primary disorders equally contributing to the visual loss, then the primary cause was assigned to one that is easiest to treat to restore vision ${ }^{10}$. In a few cases, assistance of the hospital ophthalmologist was sought for diagnosis. All participants with treatable eye conditions were referred for treatment.

Data were analysed with the Statistical Analysis System (SAS) version 9.2 software package. Categorical data analysis was used where one-way (one variable) and two-way (two variables) crosstabulation tables, frequency tables and graphs were constructed. The chi-square tests of associations between pairs of variables as well as logistic regression were performed and odds ratios were calculated and interpreted. The level of significance to test the association between variables was set at 0.05.

\section{Results}

This study was conducted among 225 participants. They included 161 (71.6\%) females and 64 (28.4\%) males and their ages ranged from 40 to 90 years with a mean of $61.50 \pm 10.49$ years. Over half (54.7\%) of the participants were 60 years older, while a few $(5.3 \%)$ were in the $45-49$ year age range. Of the 225 participants, only $12 \%$ had spectacles. Of those with uncompensated VI and blindness, $70.6 \%$ of the right eyes had VI and 3.6\% had blindness. Most (75.1\%) of the left eyes had VI and 3.1\% had blindness (Table 1).

Table 1: The categories and prevalence of uncompensated visual impairment (VI) and blindness in the right and left eyes of the participants (the sample consisted of 225, but 58 and 56, in the right and left eyes respectively did not have VI and blindness).

\begin{tabular}{|l|l|l|}
\hline Category & $\begin{array}{l}\text { Right eyes } \\
\text { N(\%) }\end{array}$ & $\begin{array}{l}\text { Left eyes } \\
\text { (\%) }\end{array}$ \\
\hline Mild VI & $23(10.2)$ & $23(10.2)$ \\
\hline Moderate VI & $126(56.0)$ & $130(57.8)$ \\
\hline Severe VI & $10(4.4)$ & $9(4.0)$ \\
\hline Blindness & $8(3.6)$ & $7(3.1)$ \\
\hline Total & $\mathbf{1 6 7 ( 7 4 . 2 )}$ & $\mathbf{1 6 9 ( 7 5 . 1 )}$ \\
\hline
\end{tabular}

In both the right and left eyes when uncompensated, there were a significant difference in percentages in the categories of VI (For the right eyes, chi-square $=132$ with 3 degrees of freedom (df) and $p<0.0001$; for the left eyes, chi-square $=145$ with 3 degrees of freedom and $\mathrm{p}<0.0001)$. The percentage of the visually impaired and blind diabetics $(74.3 \%)$ was significantly higher than that of diabetics without VI and blindness $(25.7 \%)(\mathrm{p}<0.0001)$.

Following optical compensation, the prevalence of VI and blindness based on corrected VA in the right eyes was $44.9 \%$ (41.3\% for VI; 3.6\% for blindness) and $55.1 \%$ had normal vision (Table 3 ). In the left eyes, the prevalence of VI and blindness was $45.3 \%$ (42.2\% for VI, 3.1\% for blindness) (Table 2). There was a significant difference in the prevalence of VI and blindness in the right and left eyes, chi-square $=144, d f=3, p<0.0001$; left eye: chi-square $=135$, $d f=3, p<0.0001)$. 
Table 2: The categories and prevalence of compensated visual impairment (VI) and blindness in the right and left eyes of the participants (After optical compensation, 124 and 123 of the right and left eyes respectively did not have VI and blindness).

\begin{tabular}{|l|l|l|}
\hline Category & $\begin{array}{l}\text { Right eyes } \\
\text { N(\%) }\end{array}$ & $\begin{array}{l}\text { Left eyes } \\
\text { N(\%) }\end{array}$ \\
\hline Mild VI & $15(6.7)$ & $21(9.3)$ \\
\hline Moderate VI & $70(31)$ & $67(29.8)$ \\
\hline Severe VI & $8(3.6)$ & $7(3.1)$ \\
\hline Blindness & $8(3.6)$ & $7(3.1)$ \\
\hline Total & $\mathbf{1 0 1 ( 4 4 . 9 )}$ & $\mathbf{1 0 2}(\mathbf{4 5 . 3 )}$ \\
\hline
\end{tabular}

Table 3: The causes of visual impairment (VI) and blindness based on uncompensated visual acuity values, number $(\mathrm{N})$ and percentages ( $\%$ ) of participants. 'Others' refers to causes such as stroke (as reported by participant), strabismus, retinal scars, etc.

\begin{tabular}{|l|l|l|}
\hline Causes & $(\boldsymbol{N})$ & $(\mathbf{\% )}$ \\
\hline RE & 90 & 49.5 \\
\hline Cataract & 45 & 24.7 \\
\hline Cataract and RE & 18 & 9.9 \\
\hline Others & 9 & 4.9 \\
\hline DR & 7 & 3.8 \\
\hline Glaucoma & 4 & 2.2 \\
\hline DR and RE & 2 & 1.1 \\
\hline Glaucoma and RE & 2 & 1.1 \\
\hline Amblyopia and RE & 2 & 1.1 \\
\hline Amblyopia & 1 & 0.6 \\
\hline Corneal opacity & 1 & 0.6 \\
\hline $\begin{array}{l}\text { Corneal opacity and } \\
\text { cataract }\end{array}$ & 1 & 0.6 \\
\hline Total & $\mathbf{1 8 2}$ & $\mathbf{1 0 0}$ \\
\hline
\end{tabular}

The prevalence of both the uncompensated $(58.1 \%)$ and compensated (29.3\%) VI and blindness in the right eyes of the participants was highest among those aged 60 years and older. There was no significant association between uncompensated
$\mathrm{VI}$ and blindness and age $(\mathrm{df}=4$, chi-square $=5.7$, $p=0.222$ ). However, following optical compensation, there was a significant association between these variables $(\mathrm{df}=4$, chi-square $=11.2, \mathrm{p}=0.02)$. The main causes of VI and blindness (in decreasing order) based on habitual VA are shown in Table 3. The total number of participants (182) in Table 3 is more than the 169 reported previously in Table 1. This is because a participant may be visually impaired due to more than one cause. For instance, RE may be the cause in one eye and cataract the cause in the other as illustrated in Table 3.

The prevalence of VI and blindness due to RE was higher in the right eyes of males $(62 \%)$ than in those of females $(44.4 \%)$. However, cataract was more prevalent (Figure 1) in the right eyes of females $(36.7 \%)$ than in those of males $(22 \%)$. In the left eyes, the prevalence due to RE among the males was $52.8 \%$ and among the females was $42.7 \%$ (Figure 2). The prevalence due to cataract was $22.6 \%$ and $39.3 \%$ among the males and females respectively (Figure 2).

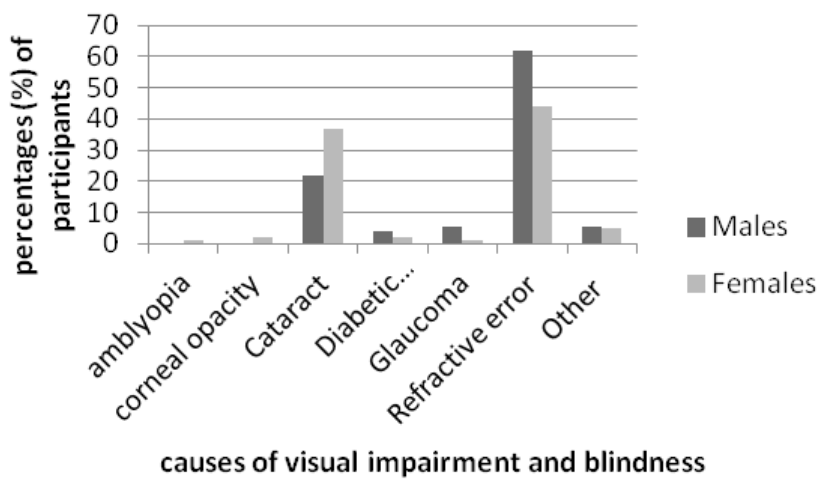

Figure 1: The causes of visual impairment and blindness in the right eyes of males and females.

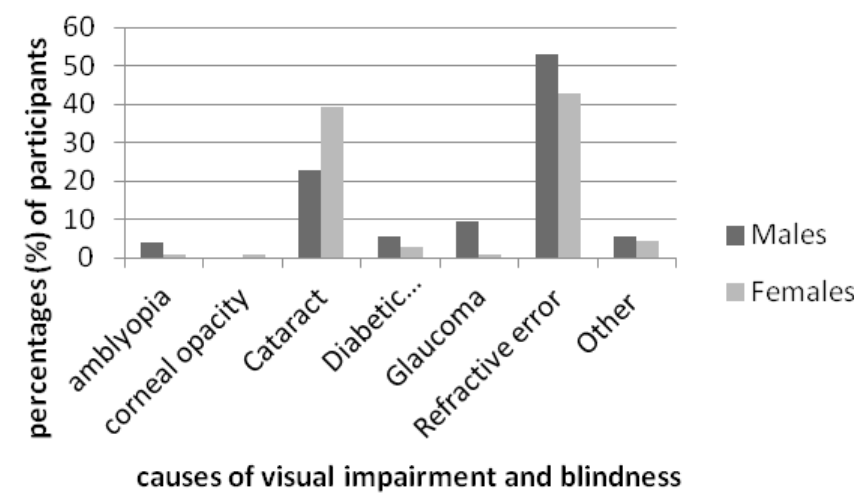

Figure 2: The causes of visual impairment and blindness in the left eyes of males and females. 
In both eyes of the participants, cataract was the major cause of VI and blindness among those aged $\geq 60$ years. However, below the age of 60 years, RE was the major cause. Following optical compensation, the leading cause of VI and blindness in both eyes of the participants was cataract (76.8\%) (Table 4).

Table 4: The causes of visual impairment and blindness in eyes of participants following optical compensation.

\begin{tabular}{|l|l|l|}
\hline Causes & Number $(\boldsymbol{N})$ & Percentage $(\mathbf{\%})$ \\
\hline Cataract & 86 & 76.8 \\
\hline Other & 9 & 8 \\
\hline DR & 8 & 7.1 \\
\hline Glaucoma & 4 & 3.6 \\
\hline Amblyopia & 3 & 2.7 \\
\hline Corneal opacity & 2 & 1.8 \\
\hline Total & $\mathbf{1 1 2}$ & $\mathbf{1 0 0}$ \\
\hline
\end{tabular}

Cataract was the leading cause of compensated VI and blindness in the right (76.5\%) and left eyes (75.8\%) (Figure 3).

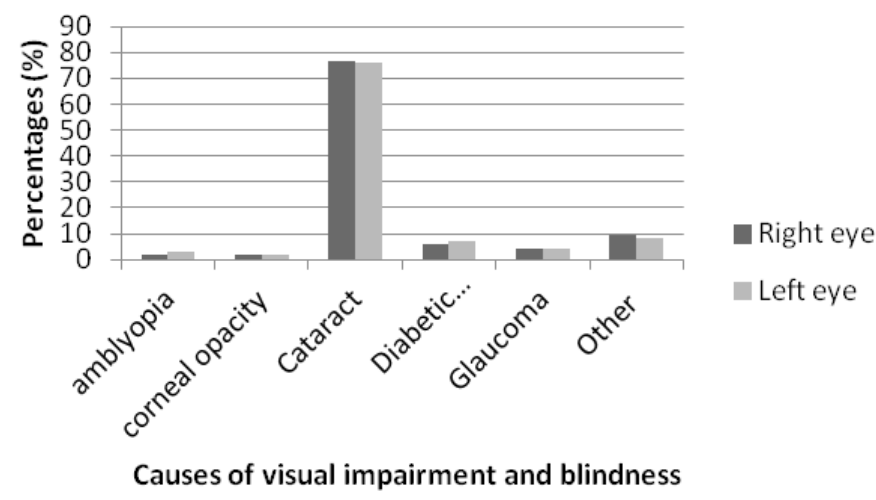

Figure 3: The causes of visual impairment and blindness in the right and left eyes of the participants.

Cataract was more common in the right eyes of females $(78.3 \%)$ than in those of males $(70.4 \%)$. Also, cataract was more prevalent in the left eyes of females $(82 \%)$ than in males $(59 \%)$. Glaucoma was more common in the right eyes of males $(11.1 \%)$ than in females $(1.4 \%)$. Also, glaucoma was more common in the left eyes of the males $(9.4 \%)$ than of the females $(1.5 \%)$. DR was more prevalent in right eyes of the females $(7.2 \%)$ than of the males $(3.7 \%)$. However, in the left eyes, it was more prevalent in the males $(9.4 \%)$ than in females $(4.5 \%)$.

\section{Discussion}

For effective planning of eye care service delivery for diabetic patients, health authorities need data on the prevalence and causes of visual impairment and blindness among people with DM. This study was therefore necessary to provide such data among Black South Africans aged 40 years and older with DM in the Mopani District. This age range (40 years and older) was chosen because diabetic ocular complications are common among this age range ${ }^{11}$. Many $(68.9 \%)$ of the participants in this study lived in rural areas where health services are limited and this might have contributed to the high prevalence of VI and blindness.

About a third (28.9\%) of participants were from the Letaba hospital presumably due to the fact that historically, diabetes management services were available only in hospitals ${ }^{12}$. A large proportion of participants were in the older age group (60-90 years) presumably because such groups are more likely to utilise the public health services. In addition, prevalence of DM might be higher in the older age groups as has been reported by previous authors in South Africa ${ }^{13,14}$ and other African countries ${ }^{15,16}$.

Some authors ${ }^{17,18}$ have reported the prevalence of VI and blindness in patients with DM using habitual VA's whereas others ${ }^{19,} 20$ used compensated (aided) VA's. Habitual VA's had been used to enable the report of prevalence of VI due to RE, which has been found to be the leading cause of $\mathrm{VI}^{21}$. The habitual VA and compensated VA methods were employed in this study to make it possible to compare findings with others, irrespective of the method used.

The prevalence of uncorrected VI reported in the present study is higher than those reported in other studies ${ }^{17-19}$. The reason for the higher prevalence might be the differences in the definition of VI and blindness, age of the participants, study sites and the population studied. For instance, in some studies ${ }^{17,18}$ VA's of equal to or better than 6/12 or equal to or better than 6/18 were considered normal; whereas in the present study these were considered as VI. Also, the inclusion of only those aged 40 years and older 
in this study might have increased the impairment prevalence as increasing age has been reported as a risk factor for VI among persons with diabetes ${ }^{17}$.

Approximately $87 \%$ of people with VI have been reported to reside in developing countries ${ }^{22}$. Visual impairment including blindness are expected to be higher in developing countries especially among those living in rural areas due to poor health care services, poor availability and accessibility of eye care services. These are the situations in the present population and this may further explain the higher prevalence of VI and blindness in this study. Clinic-based studies have been found to overestimate the frequency and severity of diseases ${ }^{23}$, this may further explain the higher prevalence of VI in this study. However, a lower value $(5.4 \%)$ of corrected VI among diabetics compared to those in this study has been reported in America $^{27}$. Similarly, lower values $(3.6 \%, 5.5 \%)^{15,25}$ have been reported in other developing countries and $12.3 \%$ in South Africa ${ }^{26}$. These lower values compared to the $41.3 \%$ in the present study may be due to several factors which include younger subjects in the study sample, urban-rural differences and differences in methodology ${ }^{15},{ }^{19}$. Duration of diabetes may also contribute to differences in prevalence values. For example, $52 \%$ of the patients in Yemen ${ }^{27}$ had diabetes for $>10$ years, compared to only $29.3 \%$ with similar duration in this study.

The statistically significant association between corrected VI and blindness and increasing age $(p=0.02)$ in this study is consistent with previous studies ${ }^{25,28}$. Age being associated with visual impairment can be explained by the fact that DM prevalence increases with age ${ }^{15}$, also, duration of diabetes is likely to be higher among the older age groups. In Pakistan, diabetics older than 60 years have been reported to be seven times more likely to develop VI than those who were 60 years and younger ${ }^{29}$. Although there was a higher percentage of VI among males in the present study, the association between VI and blindness and gender was statistically insignificant $(p=0.385)$ and is consistent with a previous report ${ }^{25}$. However, other studies have reported that diabetic females were at significantly higher risk of VI and blindness than males $^{19,28}$. There is no obvious explanation for the higher percentage of VI among males than females in the present study.
This study showed that the leading causes of uncompensated VI were RE and cataract. VI due to these conditions can be reversed by using spectacles and cataract surgery. This implies that about $50 \%$ of the participants are needlessly visually impaired. However, the leading causes of VI after optical correction were cataract and DR (Table 4). Poor accessibility and affordability of eye care service to this population may be responsible for this. That cataract was the common cause of VI and blindness followed by DR among this diabetic population (Table 4) is similar to previous reports that found cataract to be the leading cause in many countries ${ }^{15,24,30}$. The possible explanation for this is that cataract is generally an age-related condition and many of the participants were 60 years and older. Also, persons with DM are at higher risk of developing cataract compared to those without diabetes ${ }^{1}$. However, in other previous studies ${ }^{24},{ }^{31} \mathrm{DR}$ was found to be the major cause of VI and blindness. The high prevalence and severity of DR among diabetics has been attributed to the prevalence of well-established risk factors for DR progression, which include hypertension and poor glycaemic control in the population ${ }^{32}$.

This study has some limitations; therefore, the results should be interpreted with caution. The health facility-based nature of this study could have introduced a health-seeking bias and might have led to an over-estimation of the proportion of the visually impaired. The fact that VI was determined based on VA only might have excluded those who were visually impaired due to visual field loss and thus underestimated the prevalence of VI. In addition, the high prevalence of cataracts might have led to the underestimation of diseases such as DR and glaucoma. Despite these limitations, this study provides a valuable insight into the magnitude of the problem in the community and contributes to African data on visual impairment among diabetics. This data will be useful to the South African health authorities for the planning for eye care service delivery in general and among people with DM in particular.

\section{Conclusion}

Cataract and uncorrected RE were the common causes of visual impairment and blindness among this population. About $84 \%$ of the participants were 
visually impaired due to one or both of these treatable conditions. This indicates the need for affordable vision examination, spectacles provision and cataract surgery services in this population. It is presumed that the socio-economic status of this population contributed significantly to these findings, therefore government should intensify its efforts to improve the socio-economic status of people living in the rural community.

\section{Acknowledgements}

We would like to thank Professor P Ndlovu and Ms MA Managa (statisticians from UNISA), for helping with data analysis. We are also grateful to Mr Idon Sibuyi (optometrist), for helping with data collection.

\section{References}

1. International Diabetes Federation. Diabetes: A Global Threat. Diabetes Atlas, $3^{\text {rd }}$ edition. 2006. www.eatlas.idf. org/ webdata/docs/background opening pc.pdf (Accessed 26/08/2009).

2. International Diabetes Federation. Diabetes: The Global Burden. Diabetes Atlas, $5^{\text {th }}$ edition. 2011. http://www.eatlas. idf.org/print/ diabetesatlas/5e/the-global-burden (Accessed on $05 / 11 / 2011$ ).

3. Centres for Disease Control and Prevention. National Diabetes Fact Sheet: General Information and National Estimates on Diabetes in the United States, 2007. 2008. http://www.cdc.gov/ diabetes/pubs/pdf/ndfs 2007.pdf (Accessed 16/07/12).

4. Watkins PJ. ABC of diabetes: Retinopathy. Br Med J 2003 326 924-926.

5. South African Department of Health. National Guideline on Prevention of Blindness in South Africa. Directorate: Chronic Diseases, Disabilities and Geriatrics, December 2002.

6. Ferris FL, Kassoff A, Bresnick GH. New visual acuity chart for clinical research. Am J Ophthalmol 198294 91-96.

7. Oduntan OA, Mashige KP, Raliavhegwa-Makhado M. A comparison of two methods of logMAR visual acuity scoring for statistical analysis. S Afr Optom 200968 155163.

8. World Health Organization. ICD Update and Revision Platform: Change Definition of Blindness, 2011. http:// www.who.int/ blindness/en/ (Accessed 11/11/2011).

9. Dandona R, Dandona L, Srinivas M, Sahare P, Narsaiah S, Munõz SR, Pokharel GP, Ellwein LB. Refractive errors in children in a rural population in India. Invest Ophthalmol Vis Sci 200243 615-622.
10. Wei M, Chen H, Fan YC, Pathai S. Prevalence and causes of visual impairment and blindness in Sichuan Province of China. Int J Ophthalmol 20103 83-88.

11. Alexander LJ. Primary Care of the Posterior Segment, 2nd edition. Norwalk, Connecticut: Appleton \& Lange, 1994.

12. Cullinan K. Health Services in South Africa: A Basic Introduction. Health-e News Service, 2006 (Accessed 24/07/2012).

13. Clarke-Farr PC, Nel MM, Wilkinson AC. An investigation into diabetic patients' knowledge of diabetes and its ocular complications in the Western Cape. S Afr Optom $2006 \mathbf{6 5}$ 134-143.

14. Mashige KP, Notshweleka A, Moodley S, Rahmtoola FH, Sayed SB, Singh S, Sardiwalla Z. An assessment of the level of diabetic patients' knowledge of diabetes mellitus, its complications and management in Durban, South Africa. S Afr Optom 200867 95-105.

15. Onakpoya OH, Adeoye AO, Kolawole BA. Determinants of previous dilated eye examination among type II diabetics in Southwestern Nigeria. Eur J Intern Med 201021 176-179.

16. Sobngwi E, Ndour-Mbaye M, Boateng KA, Ramaiya KL, Njenga EW, Diop SN, Mbanya JC, Ohwovoriole AE. Type 2 diabetes control and complications in specialised diabetes care centres of six sub-Saharan African countries: The Diabcare Africa study. Diab Res Clin Pract 201295 30-36.

17. Sivaprasad S, Gupta B, Gulliford MC, Dodhia H, Mann S, Nagi D, Evans J. Ethnic variation in the prevalence of visual impairment in people attending diabetic retinopathy screening in the United Kingdom (DRIVE UK). 2012. PLOS ONE 7 e39608.doi:10.1371/journal.pone.0039608. http://www.plosone.org (Accessed 20/07/2012).

18. Fung MM, Yap MK, Cheng KK. Correctable visual impairment among people with diabetes in Hong Kong. Clin Exp Optom 201093 453-457.

19. Saaddine JB, Narayan KMV, Engelgau MM, Aubert RE, Klein R, Beckles GLA. Prevalence of self-rated visual impairment among adults with diabetes. Am J Public Health 199989 1200-1205.

20. Roy MS. Diabetic retinopathy in African Americans with type 1 diabetes: The New Jersey 725. Arch Ophthalmol 2000118 97-104.

21. World Health Organization. Visual Impairment and Blindness. Fact Sheet $N^{o}$ 282, 2012. http://www.who.int/ mediacentre/ factsheets/fs282/en/index/html (Accessed 10/07/2012).

22. Resnikoff S, Pascolini D, Etya'ale D, Kocur I, Pararajasegaram R, Pokharel G, Mariotti SP. Global data on visual impairment in the year 2002. Bull World Health Organ 200482 844-851.

23. Williams R, Airey M, Baxter H, Kennedy-Martin T, Girach A. Epidemiology of diabetic retinopathy and macula oedema: a systematic review. Eye 200418 963-983.

24. Klein R, Klein BEK. Vision disorders in diabetes. In: Harris MI, editor. Diabetes in America, $2^{\text {nd }}$ edition. National Diabetes Data Group.

25. Horri N, Farmani M, Ghassami M, Haghighi S, Amini M. 
Visual acuity in an Iranian cohort of patients with Type 2 diabetes: the role of nephropathy and ischemic heart disease. J Res Med Sci 201116 s419-s426.

26. Rotchford AP, Rotchford KM. Diabetes in rural South Africa- an assessment of care and complications. S Afr Med J 200292 536-41.

27. Bamashmus MA, Gunaid AA, Khandekar RB. Diabetic retinopathy, visual impairment and ocular status among patients with diabetes mellitus in Yemen: a hospital based study. Indian J Ophthalmol 200957 293-298.

28. Mvitu Muaka M, Longo-Mbenza B. Causes of visual disability among Central Africans with diabetes mellitus. Afr Health Sci 201212 193-197.

29. Shaikh A, Shaikh F, Shaikh ZA, Ahmed J. Prevalence of diabetic retinopathy and influence factors among newly diagnosed diabetics in rural and urban areas of Pakistan: Data analysis from the Pakistan national blindness and visual impairment survey 2003. Pak J Med Sci 200824 774-779.

30. de Fine Olivarius N, Siersma V, Almind GJ, Nielsen NV. Prevalence and progression of visual impairment in patients newly diagnosed with clinical Type 2 diabetes: A six-year follow-up study. BMC Public Health 20111180.

31. Hove MN, Kristensen JK, Lauritzen T, Bek T. The prevalence of retinopathy in an unselected population of Type 2 diabetes patients from Arhus County, Denmark. Acta Ophthalmol Scand 200482 443-448.

32. Smith TST, Szetu J, Bourne RRA. The prevalence and severity of diabetic retinopathy, associated risk factors and vision loss in patients with Type 2 diabetes in Luganville, Vanuatu. Br J Ophthalmol 200791 415-419. 